\title{
Identifying Bird Traits that Enable them to Become Urban Exploiters in an Urban Area of Mardan, Pakistan
}

\author{
Asif Sadam*, Rahmat Ullah Khan and Sajid Mahmood \\ Department of Zoology, Hazara University, Mansehra, 21300, Pakistan
}

\begin{abstract}
A B S T R A C T
The expansion of urban landscape causes shift in biodiversity. This study aimed to identify the traits that enable bird species to become urban exploiters i.e. to colonize and become abundant in highly urbanized areas. Bird species were identified in point counts without distance estimation, in three habitats: urban area, residential area, and agricultural area. Twelve sampling sites were selected in well-defined habitats in Mardan district. Bird species traits were taken from field observations and published literature. The trend and variation in traits was recorded along a sampled gradient of decreasing urbanization from urban area to agricultural area within district Mardan. These traits were compared among urban exploiters, adopters and avoiders. Thirty-five species were recorded out of which 9 species were urban exploiters, 11 species were urban adopters and 15 species urban avoiders. Urban exploiters were significantly $(P<0.05)$ more gregarious than adopters and avoiders. Significant $(P<0.05)$ differences were recorded in feeding behavior, such that, with increasing urbanization the proportion of omnivorous and granivorous species increased while the proportion of species feeding on invertebrates declined. It is concluded that exploitation of urban areas by some species depends on the combination of traits such as gregarious behavior, diet, sedentariness and specific nesting sites.
\end{abstract}

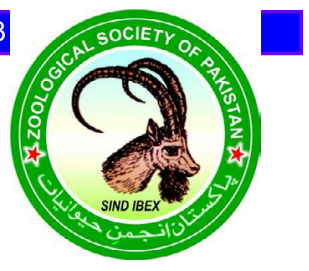

\section{INTRODUCTION}

$I^{n}$ n developing countries average human population is increasing day by day, due to which half of total global population has shifted towards urban environments. According to report projections, the current world population of 7.8 billion is expected to reach 8.5 billion by $2030,9.7$ billion in 2050 and 11.2 billion in 2100 (United Nations estimates elaborated by Worldometer, 2020). Urbanization is the process of increasing human development especially from urban areas to the neighboring natural areas (Alig and Healy, 1987; Biamonte et al., 2011). Decline of urban biodiversity is often associated with alteration of habitats caused by urbanization (Wilcox and Murphy, 1985).

As cities become more developed and enlarged, the natural habitats occupied by bird species are vanished due to which local bird diversity turns down dramatically (Marzluff, 2001; Miller and Hobbs, 2002). Birds usually possess low species richness in most developed regions compared to adjacent natural habitats, while urban centers exhibit the lowest bird diversities (McKinney, 2002). Urban development may be directly associated with the loss of biological diversity by promoting the loss of

\footnotetext{
* Corresponding author: saddamasif2@gmail.com 0030-9923/2021/0005-1813 \$ 9.00/0

Copyright 2021 Zoological Society of Pakistan
}

habitats occupied by various species (McKinney and Lockwood,1999; McKinney, 2006). However, the bird diversity decrease in highly urbanized areas is not firmly monotonic, as the bird species richness is often higher in the habitats with moderate level of development (Lepczyk et al., 2008). Migratory bird species are dilapidated more rapidly than the resident ones and may be more susceptible to environmental challenges (Wilcove and Wikelski, 2008); they also emerge to be declining in numbers in highly developed areas than the native species (Rodewald and Bakermans, 2006). Before the arrival of migrants, the resident or native species may have established their territories on the breeding grounds, due to which migrants are disadvantaged of scarce food resources. Migrants also seem to be more susceptible to environmental changes, breeding time periods and available food (Post et al., 2009); may thus turn the urban environment inappropriate for migrants. In highly urban landscapes increased human development influences bird abundance and other kind of resources essential for bird life such as diet, water, roosts and nesting locations (Mills et al., 1989). Usually, intermediate level of urbanization increases water source availability, decorative vegetation, plants and amount of periphery stuck between habitats. High level of urbanization however minimizes all these features by permanently replacing them with buildings and pavement covers (Sisk et al., 1997). It is often proposed that one reason for urban exploitation by most bird species is 
better food availability in the urban environment than their adjacent surroundings (Anderies et al., 2007). Another important factor enabling species to exploit cities may be social foraging, given the confirmed settlement of flocking in detecting enemies, learning about new food sources and food situating (Gillies et al., 2011). On the contrary, nesting sites for most bird species may be less in cities due to reduction and fragmentation of natural habitat (Davies et al., 2009), though cavity nesters exceptionally may take the advantage to colonize buildings and cavities in the city (Kark et al., 2007).

Blair (1996) divided bird communities in three different groups on the basis of increasing gradient of urbanization in his pivotal Northern California study (Blair, 1996). The gradient is established from intermediate developed area to highly developed area i.e. the downtown region. In undisturbed areas with well-developed vegetation structure, the community was occupied by urban avoiders. These species were native and occurred exclusively in these areas. In semi developed areas the sub urban adopters were the dominant species which were both resident and non-resident in origin.

In the most developed area with high level of urbanization, where buildings and pavements increase, small groups of species were dominant which Blair (1996) expressed as urban exploiters. In these highly developed areas resident species were fewer in number because of the destruction of their native habitats (Melles et al., 2003). The process in which the small group of species dominate and become able to adapt to extremely urbanized habitats (urban exploiters) replaced a large number of resident species in numerous areas of the world, is termed biotic homogenization (McKinney, 2002; Crooks et al., 2004).

The conversion of habitats into well-developed landscapes and the formation of similar ecological developments in diverse areas has resulted in the creation of homogeneous urban communities (Blair, 2001). This change in dominance is possibly due to the fact that several species known as urban avoiders do not adapt to environmental challenges enforced by extreme development (Blair, 1996; McKinney, 2002; Clergeau et al., 2006). While various species may get advantage and exploit developed slots of the city, these urban species are specialists in utilizing ecological transformations caused by increased human development (Blair, 1996). Whereas some avian species explore and colonize extreme urban landscapes, others are expelled. The question is which traits facilitate a bird species to become a successful urban exploiter?

Some traits that are known to facilitate a species to colonize extremely developed landscapes are their capability to survive and forage in the locality of humans i.e. commensalism, the capability to utilize the assets associated with humans such as feeders, dumps and garbage (Chace and Walsh, 2006), gregariousness, low resource venture in the preservation of territories (Mills et al., 1989), and sedentariness (Chace and Walsh, 2006). Differences in nest building and feeding behavior may also take part in urban adaptation and urban exploitation.

The present study aimed to identify and report the differences among urban exploiters, adopters and avoiders. Only a few bird species of a horde of bird species in the urban landscapes are capable to successfully exploit the human dominated areas. The traits were taken from literature and compared in detail along a gradient of decreasing urbanization sampled from urban area to agricultural area within district Mardan. The species traits were then compared among three bird groups- urban exploiters, urban adopters and urban avoiders by using a field-based categorization within the study area of Mardan.

More distinctively following four hypotheses were formulated: (1) Diet: Urban exploiters will be omnivores, seed eaters or aerial insectivores, whereas the urban adopters will be fruit eaters (frugivores) or non-aerial insectivores (Blair, 1996; Kark et al., 2007). (2) Social structure: Urban exploiters will tend to be gregarious (form flocks) while urban adopters will be solitary species (Kark et al., 2007). (3) Migration status: Urban exploiters will be sedentary species that will maintain nesting sites year after year, while migrant species will be unable to colonize the most urbanized habitats of the city (Kark et al., 2007). (4) Nesting sites: Urban exploiters will mainly be cavity nesters or nesting in buildings, while adopters will nest in trees, bushes and on the ground.

\section{MATERIALS AND METHODS}

\section{Study area}

The proposed study was conducted in Mardan district located in Khyber Pakhtunkhwa (KP) province of Pakistan. The entire district lies between $34.2^{\circ}$ north latitude and $72.04^{\circ}$ east longitude (Fig. 1). The entire northern side of the District is surrounded by mountains while the south western side of the District contains fertile plains with low hills surrounding it. The summer season is very hot which starts from May to June, a quick rise in temperature reported during these months. The maximum temperature $\left(43.5^{\circ} \mathrm{C}\right)$ is recorded for the month of June. Winter (November to January) is the coldest season. The coldest months are December and January with mean minimum temperature of $0.5{ }^{\circ} \mathrm{C}$. Most of the rainfall is reported in July, August, December and January. 
Study sites

Field data were collected from three well defined habitats occurring in Mardan district (34.1989 ${ }^{\circ} \mathrm{N}, 72.0231^{\circ}$ E) located in Khyber Pakhtunkhwa province of Pakistan. The study area comprises three well defined environments:

1. Urban area: The area is located in Mardan city $\left(34^{\circ} 11^{\prime} 47.0976\right.$ ' N, $72^{\circ} 2$ ' 28.4748' E). The area is well paved and densely populated with scant vegetation. For data collection four sites in the city were Bank road, Shaheedano bazar, DHQ Hospital and Chatto Chawk.

2. Residential area. The area is located in Sheikh Malton town $\left(34^{\circ} 9\right.$ ' $1.7316^{\prime \prime} \mathrm{N}, 72^{\circ} 1$ ' 47.7048" E). The area is not highly developed and populated as the former one. The number of family houses increased from urban area to residential area. Data were collected from sector A, sector D, sector I and sector $\mathrm{H}$ of the town.

3. Agricultural area: The area is located between Sheikh Malton town and GhalaDher34 8' 2.328" $\mathrm{N}, 72^{\circ} 2$ ' 33.072" E). It has a well-developed vegetation structure compared to former two areas (Fig. 1).

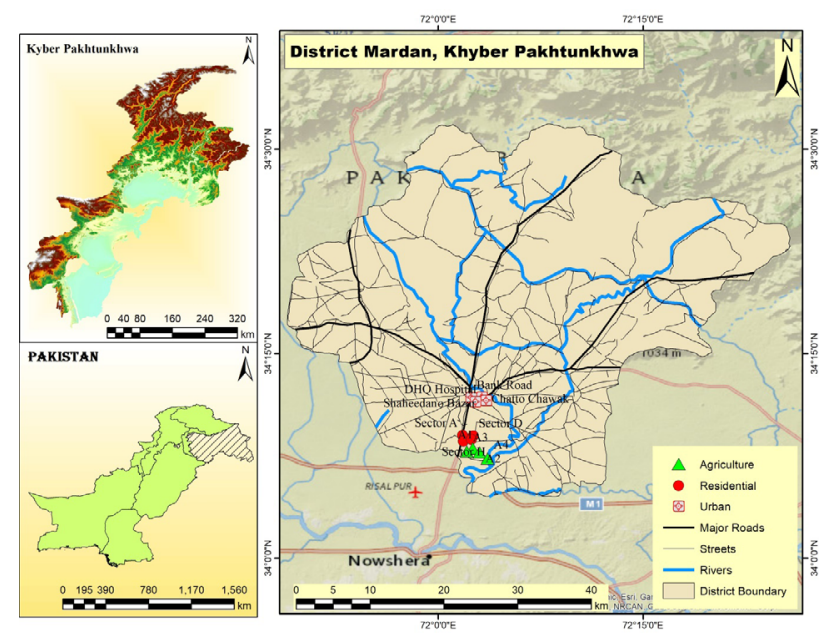

Fig. 1. Map showing urban, residential and agricultural areas respectively.

\section{Survey method}

Bird surveys were carried out from August 2017 to August 2018. The study area possesses three well defined environments (Habitats): (1) urban area (U), well paved and highly built up with little vegetation; (2) residential area $(\mathrm{R})$, less paved with low level of development and surrounding agricultural fields; and (3) agricultural area (A), with more surrounding vegetation structure and adjacent water body. For data collection point count method was used. Four sampling locations (sampling points) were selected in each of the three well defined environments viz., urban area, residential area and agricultural area i.e. twelve sampling points. Data were collected early in the morning from 8 am to $11 \mathrm{am}$. The sampling points were located approximately $1000 \mathrm{~m}$ apart. Observations were recorded for 20 minutes at each sampling point; bird species observed outside the sampling point were not recorded in order to reduce data-dependent problems. Data were recorded twice a month (Wunderle, 1994).

\section{Field based categories}

The recorded bird species were classified into urban exploiters and urban adopters on the basis of data obtained from urban area vs residential area. Urban exploiters were defined as those species that were most closely reliant on human related resources and were most abundant in urban area. Less abundant species found exclusively in residential area of Mardan were considered urban adopters. Majority of bird species recorded from agricultural lands were dependent on the water body and were called urban avoiders. These species avoided to enter into highly urban locations of the study area (Blair, 1996).

\section{Categorization of bird species traits}

Data about traits of species were collected during field observations and published literature (Cramp and Simmons, 1980; Paz and Eshbol, 1992; Shirihai et al., 1996; Del-Hoyo et al., 1999; Iwaniuk and Nelson, 2003). The traits categorized into (1) diet (classified into seed eater, insectivore, carnivore, aerial insectivore, Omnivore, eating all these food items); (2) migratory status (resident or migrant); (3) social structure (solitary, occurs in pairs, flocks of more than 10 birds and small groups with 10 or less than 10 birds); (4) Nesting sites (open nest in trees, ground, bushes, rocks, nest in buildings, holes in rocks and trees, cavities in walls and burrow tunnels). For those traits with several groups of bird species were classified in more than one group where suitable nesting location and diet were available. Where there was variation in traits in different existing landscapes, the dominant trait or behavior present in Mardan population was used. Similar with diet, if a species had many food sources in different habitats, it was classified on the basis of dominant feeding habit in that particular habitat. Classification of social structure was made in both breeding and non-breeding seasons in Mardan. Especially, for those species in which sociability in the specific habitats showed changes e.g. barn swallow and bank swallow (Kark et al., 2007). 
Table I. The classification of bird species into families and orders and their categorization into exploiters, adopters and avoiders. Used 1 for presence and 0 for absence. U, Urban; R, Residential; A, Agricultural.

\begin{tabular}{|c|c|c|c|c|c|c|}
\hline Order/Family & Common name & Scientific name & $\mathbf{U}$ & $\mathbf{R}$ & $\mathbf{A}$ & Category \\
\hline \multicolumn{7}{|l|}{ Passeriformes } \\
\hline \multirow[t]{2}{*}{ Corvidae } & House crow & Corvus splendens & 1 & 1 & 0 & Exploiter \\
\hline & Rufous treepie & Dendrocitta vagabunda & 0 & 1 & 0 & Adopter \\
\hline Pycnonotidae & Red vented bulbul & Pycnonotus cafer & 0 & 1 & 0 & Adopter \\
\hline Dicruridae & Black drongo & Dicrurus macrocercus & 0 & 1 & 0 & Adopter \\
\hline \multirow{3}{*}{ Sturnidae } & Common myna & Acridotheres tristis & 1 & 1 & 0 & Exploiter \\
\hline & Jungle myna & A. fuscus & 0 & 0 & 1 & Avoider \\
\hline & Bank myna & A. ginginianus & 1 & 1 & 1 & Exploiter \\
\hline \multirow{3}{*}{ Passeridae } & House sparrow & Passer domesticus & 1 & 1 & 0 & Exploiter \\
\hline & Tree sparrow & P. montanus & 1 & 1 & 0 & Exploiter \\
\hline & Long tail shrike & Lanius schach erythronotus & 0 & 1 & 0 & Adopter \\
\hline Laniidae & Afghan babbler & Argya huttoni & 0 & 1 & 0 & Avoider \\
\hline Leiotrichidae & White wagtail & Motacilla alba & 0 & 1 & 1 & Adopter \\
\hline \multirow[t]{3}{*}{ Motacillidae } & White browed wagtail & M. maderaspatensis & 0 & 1 & 1 & Adopter \\
\hline & Grey wagtail & M. cineria & 0 & 0 & 1 & Avoider \\
\hline & White tailed stonechat & Saxicola leucurus & 0 & 1 & 0 & Avoider \\
\hline Muscicapidae & Barn swallow & Hirundo rustica & 0 & 1 & 0 & Adopter \\
\hline Hirundinidae & Bank swallow & Riparia riparia & 0 & 1 & 1 & Adopter \\
\hline Alaudidae & Oriental skylark & Alauda gulgula & 0 & 1 & 0 & Avoider \\
\hline \multicolumn{7}{|l|}{ Columbiformes } \\
\hline \multirow[t]{4}{*}{ Columbidae } & Collar dove & Streptopelia decaocto & 1 & 1 & 0 & Exploiter \\
\hline & Laughing dove & Spelopelia senegalensis & 1 & 1 & 0 & Exploiter \\
\hline & Rock pigeon & Columba livia & 1 & 1 & 0 & Exploiter \\
\hline & Turtle dove & Streptopelia turtur & 1 & 0 & 0 & Exploiter \\
\hline \multicolumn{7}{|l|}{ Bucerotiformes } \\
\hline Upopidae & Eurasian hoopoe & Upupa epops & 0 & 1 & 0 & Adopter \\
\hline \multicolumn{7}{|l|}{ Strigiformes } \\
\hline Strigidae & Little owl & Athene noctua & 0 & 1 & 0 & Avoider \\
\hline \multicolumn{7}{|c|}{ Charadriiformes } \\
\hline Charadriidae & Red wattled lapwing & Vanellus indicus & 0 & 1 & 1 & Avoider \\
\hline Scolopacidae & Common greenshank & Tringa nebularia & 0 & 0 & 1 & Avoider \\
\hline \multicolumn{7}{|l|}{ Pelecaniformes } \\
\hline \multirow[t]{2}{*}{ Ardeidae } & Little egret & Egretta garzetta & 0 & 1 & 1 & Avoider \\
\hline & Pond heron & Ardeola grayii & 0 & 1 & 1 & Avoider \\
\hline \multicolumn{7}{|l|}{ Accipitriformes } \\
\hline Accipitridae & Black kite & Milvus migrans & 0 & 1 & 1 & Adopter \\
\hline \multicolumn{7}{|l|}{ Gruiformes } \\
\hline Rallidae & Water hen & Amaurornis phoenicurus & 0 & 0 & 1 & Avoider \\
\hline \multicolumn{7}{|l|}{ Anseriformes } \\
\hline Anatidae & Duck & Anas platyrchynchos & 0 & 0 & 1 & Avoider \\
\hline \multicolumn{7}{|l|}{ Coraciiformes } \\
\hline Coraciidae & Indian roller & Coracias benghalensis & 0 & 1 & 0 & Avoider \\
\hline Meropidae & Green bee-eater & Merops orientalis & 0 & 1 & 0 & Adopter \\
\hline \multirow[t]{2}{*}{ Alcedinidae } & Kingfisher & Halcyon smyrensis & 0 & 1 & 1 & Avoider \\
\hline & Pied kingfisher & Ceryl rudis & 0 & 0 & 1 & Avoider \\
\hline
\end{tabular}

\section{Statistical analysis}

One-way Analyses of Variance (ANOVA) were performed to test for significance in differences among the traits data recorded in different months for three well defined habitat types. We therefore compared the total number of individuals of recorded species for each 
categorical traits among three different habitats by using ANOVA to test the significant difference among exploiters, adopters and avoiders for each trait category. Two tailed t-tests were used to test for significant differences between urban exploiters and urban adopters for all traits.

\section{RESULTS}

Thirty five bird species belonging to 23 families and 10 orders were recorded in all habitats. Out of 35 bird species nine were urban exploiters, 11 urban adopters and 15 urban avoiders. All bird species recorded in urban area were also sampled in residential area except Eurasian turtle dove. Therefore, we compared the observations of urban exploiters and urban adopters from urban area and residential area (Tables I and IV).

\section{Field based analysis}

Diet category, nesting sites, sociability and migration status were all associated with level of urban expansion of the three habitat types (Table II), and assisted our identification and comparison of adopters, exploiters and avoiders.

Feeding behavior showed significant $(P<0.05)$ difference while moving from urban area to agricultural lands. In urban area 33\% species were omnivore whereas this percentage considerably declined to $16 \%$ for the species recorded in agricultural area. In highly urban locations of the city seeds were included in the diet of all species. Species feeding on fruits were absent in urban area whereas residential area attracted more fruit eaters. The proportion of carnivorous species also declined from urban to residential area but considerably improved to $33 \%$ in agricultural area. Black kite was the only carnivorous species recorded from urban and residential areas. The proportion of aerial insectivores increased from zero in urban area to $13 \%$ in residential area. This proportion considerably declined to $7 \%$ of the species occurring in agricultural lands (Table II).

Social structure showed significant $(P<0.05)$ trends along the gradient of decreasing urbanization. The proportion of species occurring in flocks considerably decreased from urban area to agricultural area. In urban location $70 \%$ species showed gregarious behavior whereas this percentage declined to $15 \%$ for the species recorded in agricultural lands. The proportion of bird species, solitary, in small groups and in pairs considerably increased from urban area to agricultural area. Thirty eight percent of bird species recorded from agricultural area were solitary. In agricultural area little egret and Indian pond heron showed dual sociability and recorded both in flocks as well as in small groups. pied kingfisher, water hen and ducks were the species recorded exclusively from the water body (Table II).

Table II. Distribution of species traits among different habitat types along the gradient of decreasing urbanization from urban area to agricultural area (the proportion of each trait each species possesses).

\begin{tabular}{|c|c|c|c|c|c|}
\hline & Region & $\begin{array}{l}\text { Ur- } \\
\text { ban }\end{array}$ & $\begin{array}{l}\text { Resi- } \\
\text { dential }\end{array}$ & $\begin{array}{l}\text { Agri- } \\
\text { cultural }\end{array}$ & $P$ \\
\hline \multirow{8}{*}{$\begin{array}{l}\text { Diet } \\
\text { catego- } \\
\text { ry }\end{array}$} & Frugivore & 0 & 0.07 & 0 & $* * *$ \\
\hline & Omnivore & 0.5 & 0.23 & 0.16 & $* * *$ \\
\hline & Insectivore & 0 & 0.3 & 0.41 & $* * *$ \\
\hline & Granivore & 1 & 0.03 & 0 & $* * *$ \\
\hline & Carnivore & 0 & 0.03 & 0.33 & $* * *$ \\
\hline & Frugivore/Granivore & 0 & 0.06 & 0 & $* * *$ \\
\hline & Insectivore/Carnivore & 0 & 0.06 & 0 & $*$ \\
\hline & Aerial insectivore & 0 & 0.13 & 0.07 & * \\
\hline \multirow{5}{*}{$\begin{array}{l}\text { Social } \\
\text { struc- } \\
\text { ture }\end{array}$} & Flocks & 0.7 & 0.33 & 0.15 & $* * *$ \\
\hline & Flock/Small group & 0.2 & 0.16 & 0.15 & $*$ \\
\hline & Small group & 0 & 0.1 & 0.23 & $* * *$ \\
\hline & Pairs & 0 & 0.06 & 0.08 & $*$ \\
\hline & Single & 0 & 0.3 & 0.38 & $*$ \\
\hline \multirow[t]{8}{*}{ Nesting } & Open nest: trees & 0.2 & 0.4 & 0.23 & $* *$ \\
\hline & Open nest: bushes & 0 & 0 & 0.15 & $* * *$ \\
\hline & Open nest: on the ground & 0 & 0.07 & 0.46 & $* *$ \\
\hline & Holes: rocks & 0 & 0.06 & 0.23 & $* *$ \\
\hline & Holes: tree & 0 & 0.06 & 0 & $* *$ \\
\hline & Buildings & 0.6 & 0.1 & 0 & $* * *$ \\
\hline & Burrows tunnel & 0 & 0.06 & 0.07 & $* * *$ \\
\hline & Cavity: wall & 0 & 0.07 & 0.23 & $* * *$ \\
\hline \multirow{3}{*}{$\begin{array}{l}\text { Migra- } \\
\text { tion }\end{array}$} & Resident & 1 & 0.45 & 0.46 & $* * *$ \\
\hline & Summer migrants & 0 & 0.45 & 0.54 & $* *$ \\
\hline & Winter migrants & 0 & 0.1 & 0 & $* * *$ \\
\hline
\end{tabular}

Nesting characteristics also showed significant $(P<0.05)$ variations along the urbanization gradient. Most species $(60 \%)$ were recorded from urban area nested in buildings. Open nesting species included species that nested in bushes, trees and on the ground. The proportion of ground nesters increased from none in urban area to $16 \%$ in agricultural area. None of the species nested in holes of rocks and tree holes in urban area. Proportion of species nesting in wall cavities and burrows/tunnels increased from none in urban area to $7 \%$ in residential and $23 \%$ in agricultural area, respectively. Cavity nesters of 
agricultural area included -pied kingfisher, white-throated kingfisher and bank myna (Table II).

Migration pattern of bird species also showed significant $(P<0.05)$ difference. All the species recorded exclusively in urban habitat were year-round resident. The proportion of summer migrants increased from zero in urban area to $54 \%$ in agricultural area. The proportion of winter migrants was higher in residential area i.e. $10 \%$.

\section{Comparison of exploiters, adopters and avoiders}

Traits such as diet, nesting, sociability and migration were used to classify bird species into three categories i.e. exploiters, adopters and avoiders. In general, most of the species possessing one trait were restricted to one category; being absent in other categories. Feeding behavior showed significant $(P<0.05)$ variations among exploiters, adopters and avoiders. Most urban exploiters (66\%) were omnivore followed by urban avoiders (13\%) and urban adopters $(9 \%)$. The proportion of granivorous species declined from $44 \%$ in exploiters to none in adopters and avoiders. The proportion of insectivores, aerial insectivores and frugivores was 36,27 and 18 percent, respectively in adopters, whereas $26 \%$ carnivorous species were urban avoiders (Table III).

Nesting behavior also showed significant $(P<0.05)$ difference among field -based categories i.e. exploiters, adopters and avoiders. The proportion of species forming open nest on trees, holes, and burrow tunnels was $36 \%$, $18 \%$ and $18 \%$ respectively in adopters compared to exploiters and avoiders (Table III). Sixty six percent of urban exploiters nested in buildings whereas none of the adopter and avoider species used buildings for their nesting. Eleven percent urban exploiter species each were recorded making nest in cavities of trees and walls; whereas this proportion considerably declined for adopters and avoiders. The proportion of ground nesters increased from zero in exploiters to $4 \%$ in avoiders (Table III).

Sociability was also significantly $(P<0.05)$ different among exploiters, adopters and avoiders. The proportion of species recorded in flocks was $88 \%$ in urban exploiters whereas this proportion declined to $27 \%$ and $13 \%$ in urban adopters and avoiders respectively. The proportion of bird species recorded in small groups was $27 \%$ in urban avoiders compared to exploiters and adopters (Table III). The proportion of species recorded in pairs (in breeding season) and solitary (non-breeding) was higher in adopters i.e. $9 \%$ and $45 \%$ respectively. Whereas this proportion slightly declined to $6 \%$ and $33 \%$ for urban avoiders (Table III).

Migratory pattern also showed significant $(P<0.05)$ differences. The proportion of year-round residents was higher in urban exploiters $(66 \%)$ compared to adopters and avoiders. Urban adopters included both summer and winter migrants. The proportion of summer and winter migrants was higher in adopters i.e. $35 \%$ and $18 \%$ respectively as compared to exploiters and avoiders (Table III).

Table III. The proportion of exploiters, adopters and avoiders for each trait category

\begin{tabular}{|c|c|c|c|c|c|}
\hline & Categories & $\begin{array}{l}\text { Ex- } \\
\text { ploiters }\end{array}$ & $\begin{array}{l}\text { Adop- } \\
\text { ters }\end{array}$ & $\begin{array}{l}\text { Avoid- } \\
\text { ers }\end{array}$ & $P$ \\
\hline \multirow[t]{6}{*}{ Diet } & Omnivore & 0.66 & 0.09 & 0.13 & $*$ \\
\hline & Seed & 0.44 & 0 & 0 & $* * *$ \\
\hline & Insectivorous & 0 & 0.36 & 0.33 & $* *$ \\
\hline & Aerial insectivore & 0 & 0.27 & 0.06 & $* * *$ \\
\hline & Carnivore & 0 & 0.09 & 0.26 & $* *$ \\
\hline & Frugivore & 0 & 0.18 & 0 & $* * *$ \\
\hline \multirow[t]{7}{*}{ Nesting } & Open nest: tree & 0.22 & 0.36 & 0.13 & $* *$ \\
\hline & Open nest: ground & 0 & 0 & 0.4 & $* * *$ \\
\hline & Building nesters & 0.66 & 0 & 0 & $* * *$ \\
\hline & Holes: rocks & 0 & 0.18 & 0 & $* * *$ \\
\hline & Burrows tunnel & 0 & 0.18 & 0.06 & $* *$ \\
\hline & Holes: tree & 0.11 & 0 & 0 & $* * *$ \\
\hline & Cavity: wall & 0.11 & 0 & 0.2 & $* *$ \\
\hline \multirow[t]{4}{*}{ Sociability } & Flocks & 0.88 & 0.27 & 0.13 & $*$ \\
\hline & Small group & 0.22 & 0 & 0.27 & $* *$ \\
\hline & Pair & 0 & 0.09 & 0.06 & $* * *$ \\
\hline & Single & 0 & 0.45 & 0.33 & $* *$ \\
\hline \multirow[t]{3}{*}{ Migration } & Resident & 0.66 & 0.27 & 0.46 & $* *$ \\
\hline & Summering & 0.33 & 0.54 & 0.53 & $*$ \\
\hline & Wintering & 0 & 0.18 & 0 & $* * *$ \\
\hline
\end{tabular}

ANOVA results: Significant * $P<0.05 ;{ }^{* *}, P<0.01 ; * * *, P<0.001$

\section{Difference between exploiters and adopters}

All urban exploiters and urban adopters showed significant $(P<0.05)$ difference for each trait category (Table IV). More urban exploiters were omnivores than adopters. Urban exploiters were more granivorous than adopters. More adopters fed on ground insects and aerial insects than exploiters. The number of frugivores and carnivores was also higher in adopters (Tables IV, V).

More urban exploiters were recorded in flocks than adopters, similarly more exploiters formed small groups than adopters. More adopters were recorded solitary (in non-breeding season) and in pairs (breeding season). Two urban exploiters were recorded in both flocks and small groups. Thus, urban exploiters appeared more social than urban adopters (Tables IV, V).

Nesting characteristics also showed difference 
between urban exploiters and urban adopters. Five urban adopters formed open nests on trees compared to exploiters. None of the exploiters nested in burrows and rock holes, whereas more adopters formed nests in burrows / tunnels and rock holes and preferred residential locations for nesting sites. Five urban exploiters nested in buildings than adopters. None of the adopters colonized the most developed parts of the city i.e. buildings. More exploiters were cavity nesters than adopters (Tables IV, V).

Table IV. Results of two tailed t-test on birds categorized into urban exploiters and urban adopters.

\begin{tabular}{lll}
\hline Traits & t-stat & $\boldsymbol{P}$ \\
\hline Omnivore & 7.11 & 0.0001 \\
Granivore & 5.51 & 0.0005 \\
Insectivorous & -5.31 & 0.0007 \\
Aerial insectivore & -5.31 & 0.0007 \\
Carnivore & -5.34 & 0.0006 \\
Frugivore & -7.34 & 0.01 \\
Open nest: trees & 3.32 & 0.01 \\
Building nesters & 8.47 & 0.000028 \\
Holes: rocks & -2.46 & 0.03 \\
Burrows tunnel & -4.87 & 0.001 \\
Holes: trees & 2.72 & 0.02 \\
Cavity: wall & 4.23 & 0.002 \\
Flocks & 5.81 & 0.0003 \\
Flock/Small group & 2.33 & 0.04 \\
Small group & -4.35 & 0.002 \\
Pair & -2.34 & 0.04 \\
Single & -3.5 & 0.008 \\
Resident & 8.35 & 0.000031 \\
Summer migrants & -2.60 & 0.05 \\
Winter migrants & -2.86 & 0.015 \\
\hline Signifant & &
\end{tabular}

Significant difference $P<0.05,0.001,0.0001$

Migratory pattern also showed difference between urban exploiters and urban adopters. Comparatively more urban adopters were migratory that showed both summer and winter migration compared to urban exploiters (Table IV, V).

\section{DISCUSSION}

Bird species traits were compared among the birds occurring in Mardan. These birds were called exploiters, adopters and avoiders based on definitions given by Blair (1996), he divided bird communities into three different groups on the basis of increasing gradient of urbanization. In undisturbed areas with well-developed vegetation structure, the community was composed of urban avoiders. In semi developed areas the sub urban adopters were the dominant species (Blair, 1996). In the most developed area with high level of urbanization, where buildings and pavements increased, species in small groups were dominant, which Blair termed as urban exploiters. The gradient was established from urban area to agricultural area.

Table V. Bird species categorized into exploiters and adopters.

\begin{tabular}{|c|c|c|c|c|c|}
\hline Bird species & $\begin{array}{l}\text { Exploiter/ } \\
\text { adopter }\end{array}$ & Diet & $\begin{array}{l}\text { Nesting } \\
\text { site }\end{array}$ & $\begin{array}{l}\text { Socia- } \\
\text { bility }\end{array}$ & $\begin{array}{l}\text { Migra- } \\
\text { tion }\end{array}$ \\
\hline Corvus splendens & Exploiter & $\mathrm{O}^{*}$ & $\mathrm{~T}$ & $\mathrm{~F}$ & $\mathrm{R}$ \\
\hline Acridotheres tristis & Exploiter & $\mathrm{O}^{*}$ & $\mathrm{Bu}$ & $\mathrm{F}$ & $\mathrm{R}$ \\
\hline $\begin{array}{l}\text { Acridotheresging- } \\
\text { inianus }\end{array}$ & Exploiter & $\mathrm{O}^{*}$ & Ho* & $\mathrm{F}$ & $\mathrm{R}$ \\
\hline Passer domesticus & Exploiter & $\mathrm{O}^{*}$ & $\mathrm{Bu}$ & $\mathrm{F}$ & $\mathrm{R}$ \\
\hline Passer montanus & Exploiter & $\mathrm{O}^{*}$ & $\mathrm{Bu}$ & $\mathrm{F}$ & $\mathrm{R}$ \\
\hline Columba livia & Exploiter & $\mathrm{Gr}$ & $\mathrm{Bu}$ & $\mathrm{F}$ & $\mathrm{R}$ \\
\hline Streptopelia turtur & Exploiter & $\mathrm{Gr}$ & $\mathrm{Bu}$ & $\mathrm{F}$ & SM \\
\hline $\begin{array}{l}\text { Spilopelia senega- } \\
\text { lensis }\end{array}$ & Exploiter & $\mathrm{Gr}$ & $\mathrm{Bu}$ & $\mathrm{F} / \mathrm{SG}$ & SM \\
\hline $\begin{array}{l}\text { Streptopelia de- } \\
\text { caocto }\end{array}$ & Exploiter & $\mathrm{Gr}$ & $\mathrm{T}$ & $\mathrm{F} / \mathrm{SG}$ & SM \\
\hline Milvus migrans & Adopter & $\mathrm{Cr}$ & $\mathrm{T}$ & $\mathrm{F}$ & SM \\
\hline Upupa epops & Adopter & In & Ho* & $\mathrm{Pa}$ & SM \\
\hline Hirundo rustica & Adopter & $A^{*}$ & $\mathrm{~B}^{*}$ & $\mathrm{~F}$ & $\mathrm{WM}$ \\
\hline Riparia riparia & Adopter & $A^{*}$ & $\mathrm{~B}^{*}$ & $\mathrm{~F}$ & WM \\
\hline $\begin{array}{l}\text { Lanius schach } \\
\text { erythronotus }\end{array}$ & Adopter & In & $\mathrm{T}$ & $\mathrm{S}$ & $\mathrm{R}$ \\
\hline $\begin{array}{l}\text { Dendrocitta vaga- } \\
\text { bunda }\end{array}$ & Adopter & $\mathrm{O}^{*}$ & $\mathrm{~T}$ & $\mathrm{~S}$ & $\mathrm{R}$ \\
\hline Motacilla alba & Adopter & In & G & S & SM \\
\hline $\begin{array}{l}\text { Motacilla mader- } \\
\text { aspatensis }\end{array}$ & Adopter & In & G & $\mathrm{S}$ & SM \\
\hline $\begin{array}{l}\text { Dicrurus mac- } \\
\text { rocercus }\end{array}$ & Adopter & $\mathrm{A}^{*}$ & $\mathrm{~T}$ & $\mathrm{~S}$ & SM \\
\hline Pycnonotus cafer & Adopter & In & $\mathrm{T}$ & $\mathrm{SG}$ & $\mathrm{R}$ \\
\hline Merops orientalis & Adopter & $A^{*}$ & Ho* & SG & SM \\
\hline
\end{tabular}

Diet: $\mathrm{O}^{*}$, omnivore; $\mathrm{Gr}$, granivore; $\mathrm{Cr}$, carnivore; in, insectivore; $\mathrm{A}^{*}$, aerial insectivore; Nesting: T, open nest on trees; $\mathrm{Bu}$, nest in buildings; $\mathrm{Ho}^{*}$, holes in trees, $\mathrm{B}^{*}$, burrows tunnel; $\mathrm{G}$, nest on ground; Sociability: F, flocks; F/S, flocks and small groups; pa, pairs; S, solitary; R, resident; $\mathrm{SM}$, summer migrant; WM, winter migrant. 
Based on our analysis we reviewed trends in change of traits by concentrating on initial predictions. We predicted that urban exploiters would be different from adopters because of feeding behavior (the exploiters tend to be seed eaters, insect eaters, omnivore or aerial insectivores), in sociability (tend to be more social), migratory status (tend to be year round residents compared to adopters), and nesting sites (tend to nest in walls or tree cavities and buildings). In half fulfillment of our initial hypothesis, the urban exploiters differed from adopters in their social structure, sedentariness, diet (except aerial insectivores were more in adopters) and to some extent in their nesting locations (Tables III, IV, V).

\section{Urban exploiter- diet}

Feeding plays a key role in identifying the species in relation to the habitat type where that particular species may be living. Different avian species selecting a specific diet were fewer in urban sites. Urban habitats providing secondary food resources i.e. plant matter or grains to avian communities exploiting such resources (Davies et $a l ., 2009$ ) may be more in number in most developed areas than those species that feed on other food sources (Fuller et al., 2008); insectivorous species are comparatively less abundant in urban landscapes (Kark et al., 2007). Similarly seed eaters and frugivores declined in number from urban area to the relatively undisturbed one. Thus, the species found in most developed parts are seed eaters and omnivores than insectivores. This is in agreement with the previous studies (Beissinger and Osborne, 1982; Blair, 1996; Leveau, 2013). In urban locations of Mardan many species adapted to foraging on human wastes and refuse. This adaptability to novel food resources within urban complex enables these bird species to exploit new slots inside the highly urban area. Hence most of the species occurring in urban area were omnivores. None of the omnivorous species was recorded solely in residential area of Mardan. Lim and Sodhi (2004) showed that omnivorous species benefitted in temperate areas where natural food sources became scarce in winter. In Mardan the avian species mostly fed on garbage and human refuse that was available even in winter e.g. common myna, bank myna and crow were seen visiting human refuse daily. It helps urban bird species to tolerate the harsh winter season. Anthropogenic food can alter the diet of urban bird species. Diet analysis of Australian silver gull Larus novaehollandiae (an urban exploiter) revealed that their stomach contents contained $85 \%$ human discards, supporting previous studies about the ability of gulls to exploit anthropogenic foods. About $38 \%$ of energy utilized per hour by suburban Florida scrub jays (Aphelocoma coerulescens) was composed of peanuts and anthropogenic foods. Likewise, about 15\% food delivered to the nestlings of blue tits and great tits in a suburban area was composed of anthropogenic foods. Thus, urban exploiters utilizing anthropogenic foods derive extra energy and tolerate harsh urban environment compared to their rural conspecifics that are unable to exploit anthropogenic foods in highly urban centers (Coogan et al., 2018).

\section{Urban exploiter- Sociability and indigenous species}

Sociability was also hypothesized to help bird species in urban food resource utilization that may assist urban exploiter to live in urban slots in several ways. For example, moving in flocks enhances the capability of species to communicate and report new food assets, to evade predators and to triumph over competition (Sol, 2008). Finally, sociability enables species to fight with other species for feeding and food assets and to overcome predators. Overall sociability helps species to survive in harsh urban areas and the capability of a species to exploit the most developed landscapes.

The percentage of migratory species considerably improved with declining urban development, suggesting that sedentary behavior was also an essential reason to evaluate whether a species would exploit urban landscape. The capability of defending territories and nesting sites year after year may be an essential reason for survival in highly developed landscapes (Wilcove and Wikelski, 2008). It may help species to effectively inhabit novel slots inside the city. Migratory species may fail to maintain their nesting locations when they migrate from the city (Kark et al., 2007).

In the present study urban exploiters appeared more gregarious. Sedentariness was also higher in urban exploiters than adopters.

\section{Urban exploiters- nesting sites}

Nesting sites in different existing habitats also contributes to urban exploitation. This may be due to several reasons, including the absence of appropriate trees for bird species that build nests on trees and feed on natural vegetation (Lim and Sodhi, 2004). Since natural vegetation is usually scarce in highly urban area, due to which many resident bird species face difficulties in finding their desired natural nesting locations, food assets or both. In contrast, species nesting in cavities (house sparrow and rock pigeon), and species constructing their nests in rocks and buildings can more effectively exploit human surroundings in the form of large buildings for nesting (Crooks et al., 2004).

Nesting sites may be destroyed if old trees are cut down within the urban environment (Blair, 1996). Similarly, the ground and bush nesters avoid urban locations due to the 
presence of domesticated animals such as cats and dogs that threaten them.

\section{CONCLUSION AND RECOMMENDATION}

A combination of traits facilitates bird species to become urban exploiters utilizing urban habitat resources. Urban exploiters differ from adopters and avoiders in their social structure, migration status and to some extent in the choice of diet categories and nesting sites. However, some trends seen in our analysis, for example some urban adopters better consumed aerial insects than urban exploiters. We recommend that a broader analysis is required to assist the generalization of these traits among urban exploiters, urban adopters and urban avoiders. We suggest that for conservation and maintenance of high bird diversity in Mardan it is necessary to develop more natural sites within and around the city where adopters, avoiders and exploiters could persist. Such decisions will benefit future conservation of biodiversity.

\section{Statement of conflict of interest}

The authors have declared no conflict of interest.

\section{REFERENCES}

Alig, R.J. and Healy, R.G., 1987. Urban and built-up land area changes in the United States: An empirical investigation of determinants. Land Econ., 63: 215 226. https://doi.org/10.2307/3146831

Anderies, J.M., Katti, M. and Shochat, E., 2007. Living in the city: resource availability, predation, and bird population dynamics in urban areas. $J$. theor. Biol., 247: 36-49. https://doi.org/10.1016/j. jtbi.2007.01.030

Beissinger, S.R. and Osborne, D.R., 1982. Effects of urbanization on avian community organization. Condor,pp. 75-83.https://doi.org/10.2307/1367825

Biamonte, E., Sandoval, L., Chacón, E. and Barrantes, G., 2011. Effect of urbanization on the avifauna in a tropical metropolitan area. Landsc. Ecol., 26: 183194. https://doi.org/10.1007/s10980-010-9564-0

Blair, R.B., 1996. Land use and avian species diversity along an urban gradient. Ecol. Appl., 6: 506-519. https://doi.org/10.2307/2269387

Blair, R.B., 2001. Birds and butterflies along urban gradients in two ecoregions of the United States: Is urbanization creating a homogeneous fauna? In: Biotic homogenization (eds. J.L. Lockwood and M.L. McKinney). Springer, Boston, MA. pp. 3356. https://doi.org/10.1007/978-1-4615-1261-5_3

Chace, J.F. and Walsh, J.J., 2006. Urban effects on native avifauna: A review. Landsc. Urban Plann., 74: 46-69. https://doi.org/10.1016/j. landurbplan.2004.08.007

Clergeau, P., Croci, S., Jokimäki, J., KaisanlahtiJokimäki, M.L., and Dinetti, M., 2006. Avifauna homogenisation by urbanisation: Analysis at different European latitudes. Biol. Conserv., 127: 336-344. https://doi.org/10.1016/j. biocon.2005.06.035

Coogan, S.C.P., Raubenheimer, D., Zantis, S.P. and Machovsky-Capuska, G.E., 2018. Multidimensional nutritional ecology and urban birds. Ecosphere, 9: e02177. https://doi.org/10.1002/ecs2.2177

Cramp, S. and Simmons., 1980. Handbook of the birds of Europe, the Middle East and North Africa. Oxford University Press.

Crooks, K.R., Suarez, A.V. and Bolger, D.T., 2004. Avian assemblages along a gradient of urbanization in a highly fragmented landscape. Biol. Conserv., 115: 451-462. https://doi.org/10.1016/S00063207(03)00162-9

Davies, Z.G., Fuller, R.A., Loram, A., Irvine, K.N., Sims, V. and Gaston, K.J., 2009. Urban domestic gardens (XV): The extent of the resource at a national scale. Biol. Conserv., 142: 761-771. https:// doi.org/10.1016/j.biocon.2008.12.016

Del Hoyo, J., Elliott, A. and Sargatal, J., 1999. Handbook of the birds of the world. barn-owls to hummingbirds. Vol. 5. Barcelona: Lynx Edicions. PLoS Biol., 6: e188.

Fuller, R.A., Warren, P.H., Armsworth, P.R., Barbosa, O. and Gaston, K.J., 2008. Garden bird feeding predicts the structure of urban avian assemblages. Divers. Distrib., 14: 131-137. https://doi. org/10.1111/j.1472-4642.2007.00439.x

Gillies, C.S., Beyer, H.L. and St. Clair, C.C., 2011. Fine-scale movement decisions of tropical forest birds in a fragmented landscape. Ecol. Applic., 21: 944-954.

Iwaniuk, A.N. and Nelson, J.E., 2003. Developmental differences are correlated with relative brain size in birds: a comparative analysis. Can. J. Zool., 81: 1913-1928. https://doi.org/10.1139/z03-190

Kark, S., Iwaniuk, A., Schalimtzek, A. and Banker, E., 2007. Living in the city: Can anyone become an 'urban exploiter'? J. Biogeogr., 34: 638-651. https://doi.org/10.1111/j.1365-2699.2006.01638.x

Lepczyk, C.A., Flather, C.H., Radeloff, V. C., Pidgeon, A.M., Hammer, R.B. and Liu, J., 2008. Human impacts on regional avian diversity and abundance. Conserv. Biol., 22: 405-416.

Leveau, L.M., 2013. Bird traits in urban-rural 
gradients: How many functional groups are there? J. Ornithol., 154: 655-662. https://doi.org/10.1007/ s10336-012-0928-x

Lim, H.C. and Sodhi, N.S., 2004. Responses of avian guilds to urbanisation in a tropical city. Landsc. Urban Plann., 66: 199-215. https://doi.org/10.1016/ S0169-2046(03)00111-7

Marzluff, J.M., 2001. Worldwide urbanization and its effects on birds. In: Avian ecology and conservation in an urbanizing world (eds. J.M. Marzluff, R. Bowman and R. Donnell). Springer, Boston, MA. pp. 19-47. https://doi.org/10.1007/978-1-4615$1531-9 \quad 2$

McKinney, M.L., 2002. Urbanization, biodiversity, and conservation. Bioscience, 52: 883-890. https://doi. org/10.1641/0006-3568(2002)052[0883:UBAC]2. $0 . \mathrm{CO} ; 2$

McKinney, M.L., 2006. Urbanization as a major cause of biotic homogenization. Biol. Conserv., 127: 247260. https://doi.org/10.1016/j.biocon.2005.09.005

McKinney, M.L. and Lockwood, J.L., 1999. Biotic homogenization: A few winners replacing many losers in the next mass extinction. Trends Ecol. Evol., 14: 450-453. https://doi.org/10.1016/S01695347(99)01679-1

Melles, S., Glenn, S. and Martin, K., 2003. Urban bird diversity and landscape complexity: Speciesenvironment associations along a multiscale habitat gradient. Conserv. Ecol., 7: 1-22. https:// doi.org/10.5751/ES-00478-070105

Miller, J.R. and Hobbs, R.J., 2002. Conservation where people live and work. Conserv. Biol., 16: 330-337. https://doi.org/10.1046/j.1523-1739.2002.00420.x

Mills, G.S., Dunning, J.B. and Bates, J.M., 1989. Effects of urbanization on breeding bird community structure in southwestern desert habitats. Condor, 91: 416-428. https://doi.org/10.2307/1368320

Paz, U. and Eshbol, Y., 1992. Photographic guide to the birds of Israel. Ralph Curtis Publishing.

Post, E., Forchhammer, M.C., Bret-Harte, M.S., Callaghan, T.V., Christensen, T.R., Elberling, B. and Ims, R.A., 2009. Ecological dynamics across the Arctic associated with recent climate change. Science, 325: 1355-1358. https://doi.org/10.1126/ science. 1173113

Rodewald, A.D. and Bakermans, M.H., 2006. What is the appropriate paradigm for riparian forest conservation? Biol. Conserv., 128: 193-200. https:// doi.org/10.1016/j.biocon.2005.09.041

Shirihai, H., Dovrat, E., Christie, D.A. and Harris, A., 1996. The birds of Israel. Academic Press, London. pp. 503-506.

Sisk, T.D., Haddad, N.M. and Ehrlich, P.R., 1997. Bird assemblages in patchy woodlands: Modeling the effects of edge and matrix habitats. Ecol. Applic., 7: 1170-1180.

Sol, D., 2008. Do successful invaders exist? Preadaptations to novel environments in terrestrial vertebrates. Springer, Berlin, Heidelberg. pp. 127141. https://doi.org/10.1007/978-3-540-36920-2_8

Wilcove, D.S. and Wikelski, M., 2008. Going, going, gone: Is animal migration disappearing. PLoS Biol., 6: e188. https://doi.org/10.1371/journal. pbio. 0060188

Wilcox, B.A. and Murphy, D.D., 1985. Conservation strategy: The effects of fragmentation on extinction. Am. Natural., 125: 879-887.

Worldometer, 2020. Current world population. Retrieved on January 16, 2020 from https://www. worldometers.info/

Wunderle, J.M., 1994. Census methods for Caribbean land birds. Gen. Tech. Rep. SO-98. New Orleans, LA: US Dept. Agric., For. Ser, Southern For. Exp. Stat., 26: 98 . https://doi.org/10.2737/SO-GTR-98 